\title{
Initial use of endothelial progenitor cells capturing stents in paediatric congenital heart disease
}

\author{
Nuno Cabanelas, ${ }^{1}$ José D. F. Martins, ${ }^{2}$ Fátima Pinto ${ }^{2}$ \\ ${ }^{1}$ Department of Cardiology, Santarém Hospital, Santarém; ${ }^{2}$ Department of Pediatric Cardiology, Santa Marta \\ Hospital, Central Lisbon Hospital Center, Lisbon, Portugal
}

\begin{abstract}
Introduction: Stenosis, mediated by neointimal hyperplasia and thrombosis, is a major limiting factor in successful stent implantation. The introduction of a stent, coated in its endoluminal surface by antihuman CD34 antibodies with endothelial progenitor cell-capturing properties, opens the possibility of promoting a rapid and normal functioning coverage by endothelium and thus avoids both an excessive cell proliferation within stent and the need for long-term dual antiplatelet therapy. These stents, developed for adult coronary artery disease, have not yet been implanted in children or in those with congenital heart disease. Objective and methods: In this paper, we describe the implantation of Genous ${ }^{\circledR}$ stents in three children with cyanotic congenital heart disease and obstructed systemic-to-pulmonary shunts. We describe the use of this stent and address its potential feasibility in paediatric congenital heart disease. Results: To maintain the patency of two modified Blalock-Taussig shunts and one ductus arteriosus, four Genous ${ }^{\circledR}$ stents were implanted in three infants with cyanotic heart disease. All procedures were immediately successful, with resolution of stenosis and improvement in transcutaneous oxygen saturation from $66 \% \pm 3.6 \%$ to $92 \% \pm 2.6 \%$. In the follow-up, one stent had no occlusion; however, the remaining two had partial occlusion after 5 and 5.5 months, which were successfully managed with balloon dilatation preceding elective definitive surgical correction. Conclusion: In our preliminary experience, we demonstrated that Genous ${ }^{\circledR}$ stent implantation was feasible in infants with complex congenital heart disease. Additional studies with larger samples and longer follow-up are required to confirm the potential benefits of this technology in this clinical setting.
\end{abstract}

Keywords: Endothelial progenitor cells capturing stent; ductus arteriosus stent; Blalock-Taussig shunt stenting

Received: 11 April 2013; Accepted: 18 August 2013; First published online: 18 September 2013

$\mathrm{I}$ N THE CURRENT ERA OF EARLY SURGICAL CORRECTION, palliation with surgical systemic-to-pulmonary artery shunts remains a valid strategy in selected cases of duct-dependent congenital heart disease. However, obstruction of these shunts is reported to range between $6.7 \%$ and $11.8 \% .^{1-3}$

Another proposed early palliative strategy for transient pulmonary blood flow maintenance is ductus arteriosus stenting. ${ }^{4-6}$ In this case, despite improving results the success is hampered by early occlusion.

Correspondence to: N. Cabanelas, Serviço de Cardiologia do Hospital Distrital de Santarém, Avenida Bernardo Santareno, 2000 Santarém, Portugal. Tel: +351 966431810; Fax: +351243300279; E-mail: ncabanelas@gmail.com
This problem has been dealt with platelet antiaggregation, acute thrombolysis, percutaneous balloon angioplasty, or re-stenting. ${ }^{10-13}$ The latter offers excellent immediate results but stent patency is usually unsatisfactory, ${ }^{9,14,15}$ with rates of re-intervention that can reach $45 \%$ after 1 year of follow-up. ${ }^{15}$

This concerning occlusion rate is multifactorial and results from thrombotic events or neointimal hyperplasia. In adult coronary artery disease, a new strategy that is being tested to circumvent stent occlusion consists of utilising antihuman CD34 antibodies on the stent's endoluminal surface, to fix progenitor endothelial progenitor cells and quickly promote endothelialisation (Genous ${ }^{\circledR}$ R-stent; OrbusNeich Medical Technologies, Fourt Lauderdale, 
Florida, United States of America). Its use in the context of coronary revascularisation has been tested in various adult patient groups and clinical settings, with satisfactory initial results ${ }^{16-19}$ but not in children or in those with congenital heart disease.

In this article, we report the use of Genous ${ }^{\mathbb{B}}$ stent in systemic-to-pulmonary shunts or patent ductus arteriosus in neonates and infants with congenital heart disease. This approach, which may take advantage of the higher level of circulating endothelial progenitor cells in younger patients, has not been previously described in this clinical setting.

\section{Cases 1 and 2}

We describe the cases of two newborns with severe tetralogy of Fallot and hypoplastic pulmonary arteries who underwent placement of $4 \mathrm{~mm}$ Goretex ${ }^{\mathrm{R}}$ modified Blalock-Taussig shunts, each. Both developed stenosis of the modified Blalock-Taussig shunts with cyanosis, 1 day and 3 months after surgery, respectively. A significant obstruction was found in the shunt's mid-segment. After balloon pre-dilatation, stent angioplasty was performed with Genous ${ }^{\circledR}$ stents (one patient with $4 \times 15 \mathrm{~mm}$ and $4 \times 13 \mathrm{~mm}$; other with $4 \times 18 \mathrm{~mm}$ stent) with satisfactory immediate angiographic and clinical result - peripheral oxygen saturation significantly improved from $64 \%$ to $91 \%$.

Immediately after the procedures, the patients were maintained under heparin perfusion for 24 hours and were started on a double antiplatelet regimen with acetylsalicylic acid $(5 \mathrm{mg} / \mathrm{kg} /$ day $)$ and clopidogrel (1 mg/kg/day).

Elective re-catheterisation, after 5 months under dual antiplatelet therapy, exhibited partial stent occlusion in one patient. The other was re-catheterised

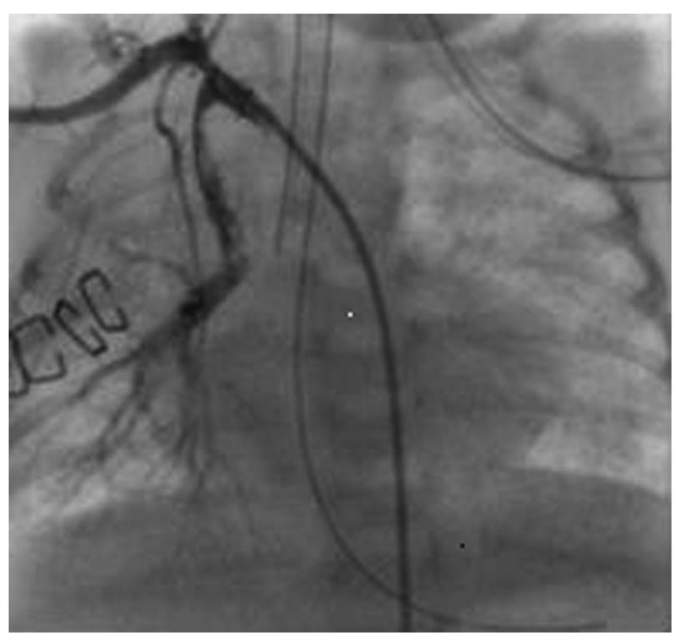

Figure 1.

Case 2 - Blalock-Taussig shunt occlusion. Antero-posterior incidence. at 10 months post-implantation, also electively, and again under the same antiplatelet regimen, and showed an adequately functioning stent.

Elective surgical correction ensued in both, successfully (Figs 1-3).

\section{Case 3}

A newborn girl with a prenatal diagnosis of pulmonary atresia and intact interventricular septum with borderline hypoplastic right ventricle - bipartite right ventricle, tricuspid valve z-score -0.4 underwent percutaneous radiofrequency pulmonary valve perforation.

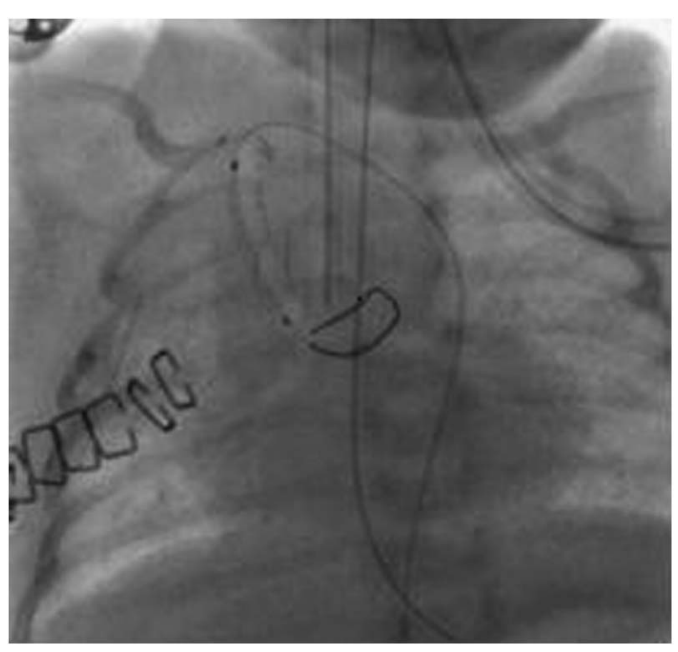

Figure 2.

Case 2 - Genous stent being deployed on Blalock-Taussig shunt. Antero-posterior incidence.

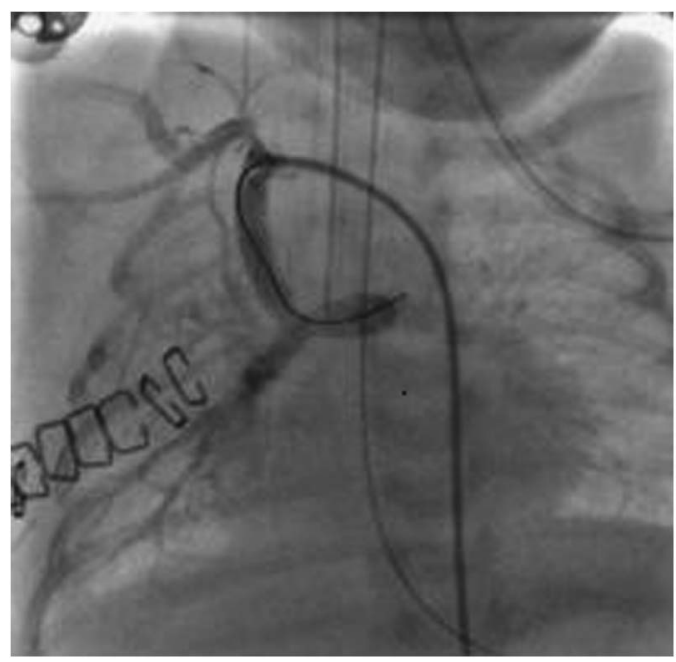

Figure 3 .

Case 2 - Blalock-Taussig shunt after stent expansion. Anteroposterior incidence. 
At 1.5 months old, despite good outflow obstruction, the right ventricle was still unsuitable for maintenance of pulmonary blood flow and the patient was dependent on a progressively restrictive patent ductus arteriosus. A narrowed patent ductus arteriosus was stented with a Genous ${ }^{\mathbb{R}}$ stent $(4 \times 9 \mathrm{~mm})$. She was discharged on a dual antiplatelet regimen with acetylsalicylic acid $(5 \mathrm{mg} / \mathrm{kg} /$ day $)$ and clopidogrel $(1 \mathrm{mg} / \mathrm{kg} /$ day $)$. At 7 months of age, she was re-admitted for severe desaturation. The catheterisation showed severe residual pulmonary valve stenosis and partial in-stent occlusion, despite dual antiplatelet therapy. Both were treated with balloon dilation, and she was discharged with an improved saturation of $95 \%$.

At 14 months, a third and final pulmonary valvuloplasty was performed, and the stented ductus was found to be adequately patent. Currently, she is 2 years old, and has an adequately functioning right ventricle and is planned for a percutaneous closure of the patent ductus arteriosus, medicated with acetylsalicylic acid.

\section{Discussion}

Stent deployment generates vascular trauma with dilatation and intimal stretch or tear, which ideally ends in its endothelialisation by mature and functional endothelial cells. However, vascular wall injury generates an inflammatory reaction involving macrophages, platelets, and fibrin accumulation along with neovascularisation, which may explain the occurrence of mural thrombi. ${ }^{20-22}$

The immediate outcome after stent deployment depends on stenosis resolution. However, a favourable mid- to long-term result is dependent on the degree of cell proliferation that occurs in its lumen, which can obstruct blood flow, particularly in smaller vessels, such as is the case of modified Blalock-Taussig shunts and patent ductus arteriosus. This problem is both common and important after coronary stenting, and thus strategies have been developed to address this issue.

After the advent of cytostatic or cytotoxic drugcoated stents, the phenomenon of excessive neointimal proliferation was reduced; however, it also resulted in a delay of endothelialisation by inhibiting the proliferation of several undifferentiated cell clusters involved in the native physiological reaction to stent implantation. Blood exposure to subendothelial prothrombotic constituents, to tissue factor and to the stent itself, predisposes to thrombosis. This justifies the need for long-term dual antiplatelet therapy until complete endothelialisation is completed, which carries increased morbidity in specific clinical settings.
In short, there are physiological processes that are intended to be prevented, namely, stenosis caused by physiological, but harmful, excessive cell proliferation inside the stent; thrombosis due to late stent endothelialisation promoted by eluted drugs used for stenosis prevention; and bleeding caused by dual antiplatelet therapy used in order to prevent thrombosis.

Identification of endothelial progenitor cells and control of their differentiation in the right site at the right time is a goal long ago pursued by scientific community in general, and that which studies ischaemic disease in particular. However, the inability to identify with high accuracy these cells has been the limiting factor for achieving this goal ${ }^{23}$ and to control angiogenesis, with all its consequent benefits in the field of ischaemic disease.

Genous ${ }^{\mathbb{R}}$ stent is composed of a grid of 316 stainless steel, coated in endoluminal surface by a polysaccharide layer containing murine monoclonal antihuman $\mathrm{CD} 34+$ antibodies, which attracts endothelial progenitor cells. ${ }^{24}$ Animal studies showed its complete endothelialisation within few days. ${ }^{21,22}$ Moreover, it is thought that the generation of an intact endothelial layer with normal homeostatic properties leads to inhibition of neointimal proliferation by production of anti-inflammatory and anti-proliferative factors. ${ }^{25-27}$ HEALING-FIM trial, the first study in humans, showed its safety, with only one out of 16 patients having a target vessel revascularisation procedure within 9 months, being only 1 month under dual antiplatelet therapy. ${ }^{17}$

In HEALING II trial, ${ }^{18}$ a prospective multicentre registry, with 63 patients with significant coronary lesions, Genous ${ }^{\mathbb{R}}$ stent had a satisfactory performance, despite the fact that the patients were treated with two antiplatelet agents for only the first month after implantation. These results were supported by those of e-HEALING registry. ${ }^{19}$

There are few data concerning the advantages of Genous ${ }^{\circledR}$ stent in thrombosis and stenosis prevention in the medium to long term, in comparison with drug eluting stents and bare metal stents. ${ }^{24}$ Currently, there is an ongoing multi-centre randomised study - TRI-stent Adjudication Study comparing antihuman CD34 antibody-coated stents, drug-eluting stents, and bare metal stents and quantifying circulating endothelial progenitor cells at the time of stent deployment.

On the basis of existing data of a short series of patients, the rate of modified Blalock-Taussig shunt occlusion was described to range from $9 \%$ to $12 \% .^{2,3}$ The physiopathology of thrombosis and endothelial hyperplasia is potentiated by surgical iatrogenesis such as shunt kinking or proximal subclavian artery stenosis, and frequently accompanying coagulation 
Table 1. Clinical case evolution.

\begin{tabular}{|c|c|c|c|c|c|c|c|}
\hline Diagnosis & Age & $\begin{array}{l}\text { No. } \\
\text { stents }\end{array}$ & Localisation & $\begin{array}{l}\text { Dimensions } \\
(\mathrm{mm})\end{array}$ & Complications & $\begin{array}{l}\text { Time to } \\
\text { complication }\end{array}$ & Treatment \\
\hline Tetralogy of Fallot & 4 months & 2 & $\begin{array}{l}\text { Blalock-Taussig } \\
\text { shunt }\end{array}$ & $\begin{array}{l}4 \times 15 \\
4 \times 13\end{array}$ & $\begin{array}{l}\text { Partial in-stent } \\
\text { stenosis }\end{array}$ & 5 months & $\begin{array}{l}\text { Balloon } \\
\text { angioplasty }\end{array}$ \\
\hline $\begin{array}{l}\text { Pulmonary atresia and } \\
\text { patent ductus } \\
\text { arteriosus }\end{array}$ & 51 days & 1 & Ductus Arteriosus & $4 \times 9$ & $\begin{array}{l}\text { Partial in-stent } \\
\text { stenosis }\end{array}$ & 5.5 months & $\begin{array}{l}\text { Balloon } \\
\text { angioplasty }\end{array}$ \\
\hline Tetralogy of Fallot & 16 days & 1 & $\begin{array}{l}\text { Blalock-Taussig } \\
\text { shunt }\end{array}$ & $4 \times 18$ & $\begin{array}{l}\text { Without } \\
\text { complications }\end{array}$ & - & \\
\hline
\end{tabular}

disturbances among congenital heart disease patients, particularly those with cyanotic disorders. Shunt occlusion requires immediate treatment. If medical thrombolysis is unsuccessful, stenting of these modified Blalock-Taussig shunts is the best option. Results showed that stent implantation is an effective treatment to improve oxygen saturation in an acute setting, having high rates of immediate success. ${ }^{10,28-30}$ However, medium- to long-term results are not so satisfactory, and there are reports in which almost one-third of the patients did not reach second stage palliation surgery. ${ }^{10}$

Arterial duct stenting has been suggested as an alternative to surgery in duct-dependent pulmonary circulation, particularly in high-risk neonates. ${ }^{7,31}$ However, despite technical advances, the durability of this approach was shorter than that of surgical shunts. Acute procedural failure is around $10 \%$, and occlusion still occurs invariably within few months. ${ }^{5,31}$ Several technical aspects are important, and results are less satisfactory when the duct has a tortuous morphology or the duct tissue is not completely covered by stents. ${ }^{14,29}$

Favourable outcomes recently demonstrated by Genous ${ }^{\circledR}$ stent in adult population of coronary patients, conceptually, open the field for its evaluation in other settings, for example in children. In addition, it is hypothesised that there is a higher proportion of circulating endothelial progenitor cells in young children, which could potentially make the mechanism of stent endothelialisation particularly efficient in this setting.

Our initial experience in a paediatric population with cyanotic heart disease showed acute success in all patients.

In the complex clinical settings reported in these three cases, in terms of traditional short and middle term stent's rate of occlusion, as mentioned earlier in this text, in this serie two out of four stents remained free of haemodynamic significant stenosis until definite correction of the cardiopathy was achieved; one stent implanted in a modified Blalock-Taussig shunt showed partial stenosis, clinically silent, in an elective procedure performed 5 months after implantation; and the remaining stent implanted in a slim patent ductus arteriosus exhibited partial stenosis, 5.5 months later, treated with percutaneous balloon dilatation (Table 1).

This is an initial report using an antihuman CD34 antibody-coated stent in the paediatric population, and these results should be looked at carefully because of the limited number of cases.

\section{Conclusion}

The benefits, in terms of prognosis and safety, of using an antihuman CD34 antibody-coated stent are now being addressed in adult patients with coronary artery disease, and initial studies had satisfactory results. We describe three cases of Genous ${ }^{\circledR}$ stent implantation in children in which the maintenance of patency of the angioplastied vessels was essential for survival, demonstrating that its use is feasible.

The potential advantages of this kind of stent over conventional stents are not yet addressed in children, and this issue obviously requires trials with larger populations comparing it directly with other types of currently commercialised stents.

\section{Acknowledgements}

The authors thank the staff of the Santa Marta's Hospital Cath Lab.

\section{Financial Support}

This research received no specific grant from any funding agency, commercial or not-for-profit sectors.

\section{Conflicts of Interest}

None.

\section{References}

1. Al Jubair K, Al Fagih M, Al Jarallah A, et al. Results of 546 Blalock-Taussig shunts performed in 478 patients. Cardiol Young 1998: 486-490. 
2. Gedicke M, Morgan G, Parry A, et al. Risk factors for acute shunt blockage in children after modified Blalock-Taussig shunt operations. Heart Vessels 2010; 25: 405-409.

3. Ahmad U, Fatimi S, Nagyi I, et al. Modified Blalock-Taussig shunt: immediate and short-term follow-up results in neonates. Heart Lung Circ 2008; 17: 54-58.

4. Qureshi S. Catheterization in neonates with pulmonary atresia with intact ventricular septum. Catheter Cardiovasc Interv 2006; 67: 924-931.

5. Santoro G, Gaio G, Palladino M, et al. Arterial duct stenting: do we still need surgical shunt in congenital heart malformations with duct-dependent pulmonary circulation? J Cardiovasc Med Hagerstown 2010; 11: 852-857.

6. Schranz D, Michel-Behnke I, Heyer R, et al. Stent implantation of the arterial duct in newborns with a truly duct-dependent pulmonary circulation: a single-center experience with emphasis on aspects of the interventional technique. J Interv Cardiol 2010; 23: $581-588$.

7. Santoro G, Gaio G, Palladino M, et al. Stenting of the arterial duct in newborns with duct-dependent pulmonary circulation. Heart 2008; 94: 925-929.

8. Hussain A, Al-Zharani S, Muhammed A, et al. Midterm outcome of stent dilatation of patent ductus arteriosus in ductal-dependent pulmonary circulation. Congenit Heart Dis 2008; 3: 241-249.

9. Alwi M. Stenting the ductus arteriosus: case selection, technique and possible complications. Ann Pediatr Cardiol 2008; 1: 38-45.

10. Gillespie M, Rome J. Transcatheter treatment for systemic-topulmonary artery shunt obstrution in infants and children. Catheter Cardiovasc Interv 2008; 71: 928-935.

11. Sutherell J, Hirsch R, Beekman R, et al. Pediatric interventional cardiology in the United States is dependent on the off-label use of medical devices. Congenit Heart Dis 2010; 5: 2-7.

12. Kogon B, Villarj C, Shah N, et al. Occlusion of the modified Blalock-Taussig shunt: unique methods of treatment and review of catheter-based intervention. Congenit Heart Dis 2007; 2: 185-190.

13. Moszura T, Zubrzycka M, Michalak K, et al. Acute and late obstrution of a modified Blalock-Taussig shunt: a two-center experience in different catheter-based methods of treatment. Interact Cardiovasc Thorac Surg 2010; 10: 727-731.

14. Krasemann T, Tzifa A, Rosenthal E, et al. Stenting of modified and classical Blalock-Taussig shunts - lessons learned from seven consecutive cases. Cardiol Young 2011; 21: 430-435.

15. Alwi M, Choo K, Kandavello $G$, et al. Initial results and medium-term follow-up of stent implantation of patent ductus arteriosus in duct-dependent pulmonary circulation. J Am Coll Cardiol 2004; 44: 438-445.

16. Miglionico M, Patti G, D’Ambrosio A, et al. Percutaneous coronary intervention utilizing a new endothelial progenitor cells antibody-coated stent: a prospective single-center registry in high-risk patients. CatheterCardiovasc Interv 2008; 71: 600-604.

17. Aoki J, Serruys P, van Beusekom H, et al. Endothelial progenitor cell capture by stents coated with antibody against CD34: the HEALING-FIM (healthy endothelial accelerated lining inhibits neointimal growth-first in man) Registry. J Am Coll Cardiol 2005; 45: 1574-1579.

18. Duckers H, Soullié T, den Heijer P, et al. Accelerated vascular repair following percutaneous coronary intervention by capture of endothelial progenitor cells promotes regression of neointimal growth at long-term follow-up: final results of HEALING II trial using an endothelial progenitor cell capturing stent (Genous $\mathrm{R}$ stent ${ }^{\mathbb{R}}$ ). Euro Intervention 2007; 3: 350-358.

19. Silber S, Damman P, Klomp $\mathrm{M}$, et al. Clinical results after coronary stenting with the Genous Bio-engineered $\mathrm{R}$ stent: 12-month outcomes of the e-HEALING (Healthy Endothelial Accelerated Lining Inhibits Neointimal Growth) worlwide registry. EuroIntervention 2011; 6: 819-825.

20. Komatsu R, Ueda M, Naruko T, et al. Neointimal tissue response at sites of coronary stenting in humans: macroscopic, histological, and immunohistochemical analyses. Circulation 1998; 98: 224-233.

21. McElhinney D, Bergersen L, Marshall A. In situ fracture of stents implanted for relief of pulmonary arterial stenosis in patients with congenitally malformed hearts. Cardiol Young 2008; 18: 405-414.

22. Farb A, Sangiorgi G, Carter A, et al. Pathology of acute and chronic coronary stenting in humans. Circulation 1999; 99: 44-52.

23. Yoder M. Defining human endothelial progenitor cells. J Thromb Haemost 2009; 7 (Suppl 1): 49-52.

24. Beijk M, Klomp M, Verouden N, et al. Genous ${ }^{\circledR}$ endothelial progenitor cell capturing stent vs the Taxus Liberté stent in patients with de novo coronary lesions with a high-risk of coronary restenosis: a randomized, single-centre, pilot study. Eur Heart J 2010; 31: 1055-1064.

25. Nakazawa G, Granada J, Alviar C, et al. Anti-CD34 antibodies immobilized on the surface of sirolimus-eluting stetns enhance endothelization. J Am Coll Cardiol 2010; 3: 68-75.

26. Kutryk M, Kuliszewski M. In vivo endothelial progenitor cell seeding for the accelerated endothelization of endovascular devices. Am J Cardiol 2003; 92 (Suppl 6A): 94L-95L.

27. Kong D, Melo L, Mangi A, et al. Enhanced inhibition of neointimal hyperplasia by genetically engineered endothelial progenitor cells. Circulation 2004; 109: 1769-1775.

28. Kaestner M, Handle R, Photiadis J, et al. Implantaion of stents as an alternative to reoperation in neonates and infants with acute complications after surgical creation of a systemic-to-pulmonary arterial shunt. Cardiol Young 2008; 18: 1777-1784.

29. Zabala-Arquelles J, Conejo-Muñoz L, Cuenca-Peiró V, et al. Ductal stenting for acute thrombosis off modified Blalock-Taussig shunts. Rev Esp Cardiol 2010; 63: 1212-1213.

30. Petit C, Gillespie M, Kreutzer J, et al. Endovascular stents for relief of cyanosis in single-ventricle patients with shunt or conduit dependent pulmonary blood flow. Catheter Cardiovasc Interv 2006; 68: 280-286.

31. Santoro G, Gaio G, Castaldi B, et al. Arterial duct stenting in low-weight newborns with duct-dependent pulmonary circulation. Catheter Cardiovasc Interv 2011; 78: 677-685. 
Copyright of Cardiology in the Young is the property of Cambridge University Press and its content may not be copied or emailed to multiple sites or posted to a listserv without the copyright holder's express written permission. However, users may print, download, or email articles for individual use. 